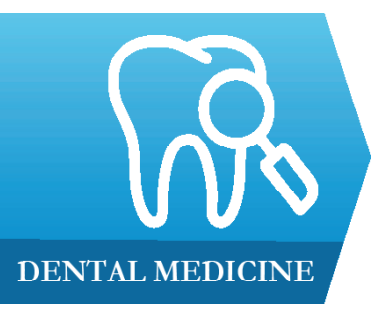

Oral Pathology and Microbiology Department, Manipal College of Dental Science's, MAHE, Manipal, India

\title{
Odontogenic cysts and odontogenic tumors in a large rural area from India. A 10-year reflection
}

Anchal Bhat, Soham Mitra, Chetana Chandrashekar, Monica Solomon, Spoorti Kulkarni

\begin{abstract}
Objectives. To determine the prevalence of odontogenic cysts and tumors along with age range, sex distribution, site of presentation and also to identify the most common type of odontogenic cyst and tumor among the population of coastal Karnataka over a 10 -year period.

Methods. Data was collected from patient records and histologically diagnosed cases of odontogenic cysts and tumors. The age, gender of patients, as well as the site of lesion was recorded.

Results. A total of 167 cases were retrieved. Among them, 125 cases were diagnosed as odontogenic cysts and 42 cases were odontogenic tumors. Radicular cyst was the most frequently diagnosed cyst and unicystic ameloblastoma was the most frequently diagnosed tumor. A strong predilection for males was observed for both the odontogenic cysts and odontogenic tumors. Odontogenic cysts were more commonly seen in individuals in the age range 21-41 years, while odontogenic tumors were frequently seen in individuals in the age range 1-20 years.

Conclusion. This study provides an epidemiological profile of odontogenic cysts and odontogenic tumors among a rural population of coastal Karnataka. There is a notable variation in demographic profile of odontogenic cysts and odontogenic tumors in this population when compared with other populations.
\end{abstract}

Keywords: odontogenic cysts, odontogenic tumors, pathogenesis, rests of Serre, rests of Malassez

\section{Introduction}

Odontogenic cysts and tumors are a diverse group of lesions originating from the tissue remnants of the tooth forming apparatus or due to inflammation $[1,2]$. A cyst may or may not be lined by epithelium. The World Health Organization (WHO) has classified epithelial cysts as odontogenic cysts which may be developmental or inflammatory in origin, and non-odontogenic cysts, namely nasopalatine and nasoalveolar. Cysts without epithelial lining (pseudocysts) are non-neoplastic bone lesions which include solitary bone cyst and aneurysmal bone cyst [3].

Developmental cysts are formed

Manuscript received: 29.01.2019

Accepted: 06.05.2019

Address for correspondence: spoorti.kulkarni@manipal.edu by activation of odontogenic cell rests entrapped within the bone tissue or gingival tissue of the jaws, such as the epithelial remains of Malassez, cell rests of Serres, or the enamel organ, whereas inflammatory cysts are associated with inflammation. They exhibit slow growth and a tendency towards expansion [4,5], causing bone or tooth resorption, fracture, or tooth displacement [6].

Odontogenic tumors comprise a heterogeneous group of lesions that develop on the gnathic bones, that ranges from hamartomas to benign and malignant neoplasms of variable aggressiveness. They are classified as epithelial, ectomesenchymal, and mesenchymal tumors, among which the most frequent odontogenic tumors are ameloblastomas, and odontomas $[7,8]$.

Despite the importance of these lesions the information regarding the demographic profile in different populations is scarce. The present study was designed to know the relative 
frequency of odontogeinc cyst and tumors, to know their clinic-pathological characteristics and to determine the frequency of odontogenic cysts and tumors concerning the age, gender distribution and the site of the lesions in coastal Karnataka population.

\section{Materials and method}

This survey was approved by the institution ethics committee (IEC 424/2016). A retrospective analysis was carried out on all the histopathologically diagnosed cases of odontogenic cysts and tumors that were reported between the years 2006 and 2016 at the Department of Oral pathology and Microbiology. They were assessed in terms of frequency, age, sex, and their anatomical distribution. To classify the location of the cysts and tumors, each jaw was divided into an anterior and a posterior zone. The anterior zone included the incisors, canines and the posterior zone consisted of premolars, molars and ramus/tuberosity.

\section{Statistical analysis}

Statistical analysis was carried out using the SPSS package (version 15). Mean $+/-\mathrm{SD}$, minimum and maximum was used to summarize the age. Frequency with percentage was used to summarize the categorical variables.

\section{Results}

The retrospective study of odontogenic cyst and tumors reported to the department of oral pathology and microbiology between 2006-2016 was performed, which consisted of total 125 cases of odontogenic cysts and 42 cases of odontogenic tumors.

Among 125 cases of odontogenic cysts, 76 $(60.8 \%)$ cases were radicular cysts, followed by 28 $(22.4 \%)$ cases of dentigerous cyst and 17 (13.6\%) cases were odontogenic keratocysts, $2(1.6 \%)$ cases of orthokeratinized odontogenic cyst, $1(0.8 \%)$, case each of calcifying odontogenic cyst, and glandular odontogenic cyst. Thus, based on statistical analysis, radicular cyst was found to be the most prevalent odontogenic cyst is this population (Figure 1).

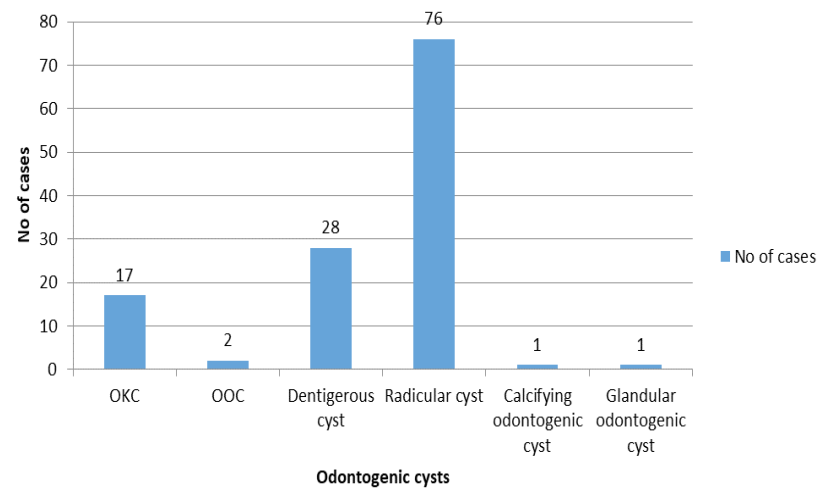

Figure 1. Frequency of odontogenic cysts among the rural coastal Karnataka population.
Out of 125 cases of odontogenic cyst 53 (42\%) cases were seen in the age range of 21 to 40 years, indicating that the odontogenic cyst occurred most commonly in the $2^{\text {nd }}$ to $4^{\text {th }}$ decades of life followed by $35(28 \%)$ cases between the age range of 1-20 years; $26(20.8 \%)$ cases occurred between 41 to 60 years and $13(10.4 \%)$ cases occurred between 61 to 80 years (Figure 2).

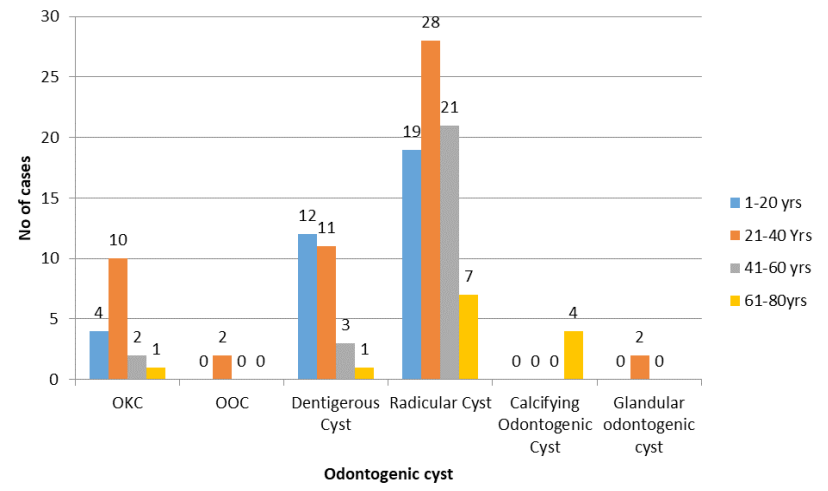

Figure 2. Distribution of odontogenic cysts among the different age groups. OKC-odontogenic Keratocyst, OOC- orthokeratinized odontogenic cyst.

Among the 125 cases of odontogenic cysts, $85(68 \%)$ of the cases occurred in males and $40(32 \%)$ cases were seen in females (Figure 3). Among the 125 cases $53(42.4 \%)$ cases were seen in the posterior mandible followed by $41(32.8 \%)$ cases in the anterior maxilla, $16(12.8 \%)$ cases in the posterior maxilla and 12 $(9.6 \%)$ cases in the anterior mandible. Hence the posterior mandible was the most common site for the odontogenic cysts (Figure 4).

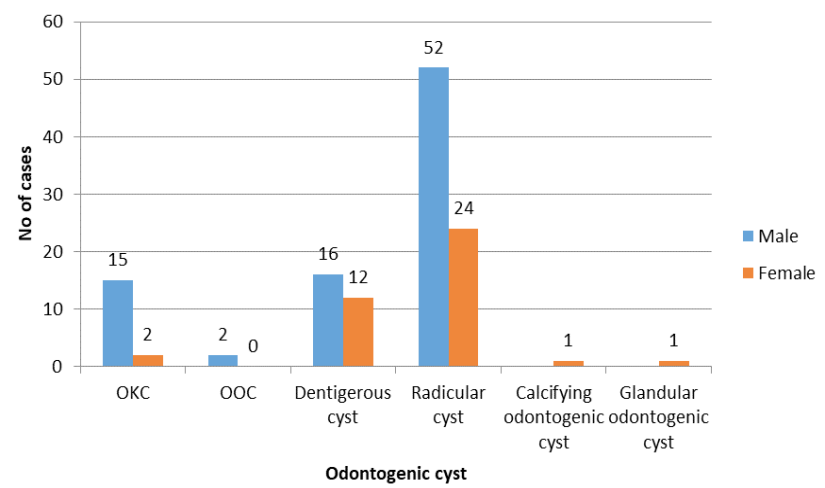

Figure 3. Distribution of the various odontogenic cysta based on the gender of the patients. OKC- odontogenic Keratocyst, OOCorthokeratinized odontogenic cyst. 


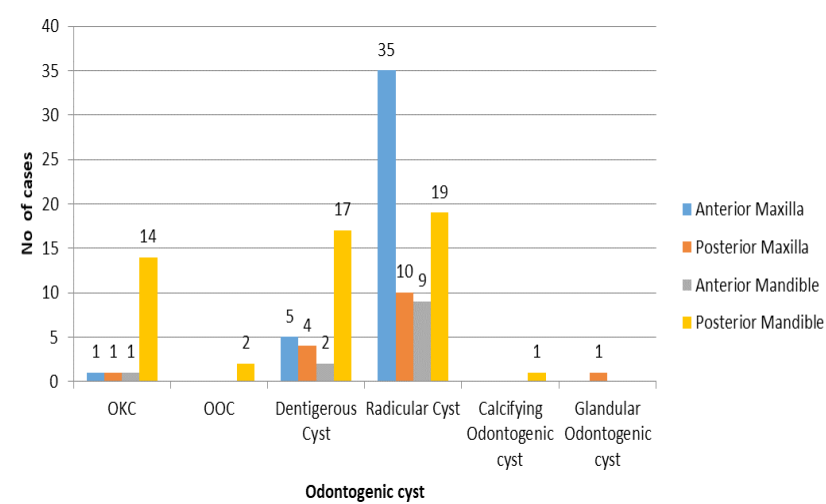

Figure 4. Distribution of odontogenic cysts based on the site of occurrence in the jawbones. OKC- odontogenic Keratocyst, OOC- orthokeratinized odontogenic cyst

Out of 42 cases of odontogenic tumors, 16 (38\%) cases were of unicystic ameloblastoma followed by 10 (23\%) cases of follicular amelobalstoma, 4 (9.5\%) cases of Plexiform unicystic ameloblastoma cases, $3(7.1 \%)$ cases of odontoma, $3(7.1 \%)$ cases of adenomatoid odontogenic tumors, $1(2.3 \%)$ cases of benign cementoblastoma, 1 $(2.3 \%)$ cases of desmoplastic ameloblastoma, 1 (2.3\%) cases of odontogenic myxoma. 2 (3.2\%) cases of peripheral odontogenic fibroma, $1(2.3 \%)$ cases of peripheral odontogenic fibroma with calcification. Thus, unicystic ameloblastoma was the most common odontogenic tumor that was manifested by this population (Figure 5).

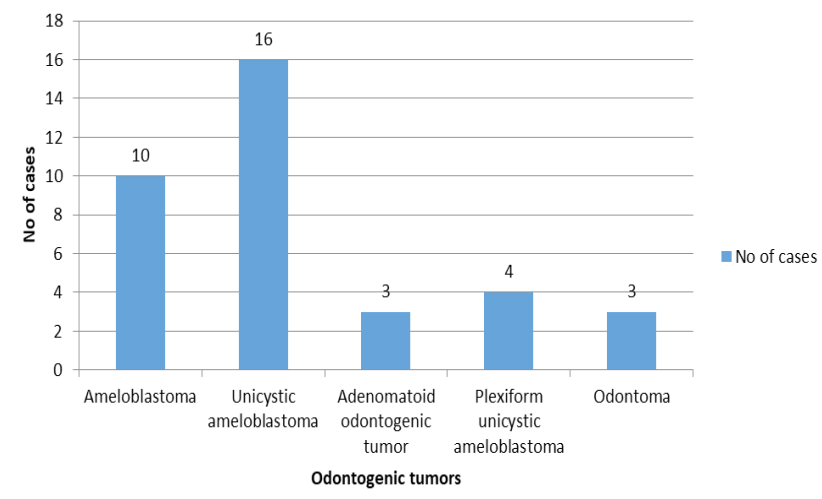

Figure 5. Frequency of odontogenic tumors among the rural coastal Karnataka population.

Among the 42 cases, 14 (33.3\%) cases occurred in the patients of the age range 1 to 20 years, 11 (26.1\%) cases in the age range of 21-40 years, $13(30.9 \%)$ cases occurred in the age range $41-60$ years and $1(2.3 \%)$ case was seen in the age range of 61-80 years (Figure 6). Among the 42 cases, $20(47.6 \%)$ cases occurred in males, while $16(38 \%)$ cases were seen in females (Figure 7).

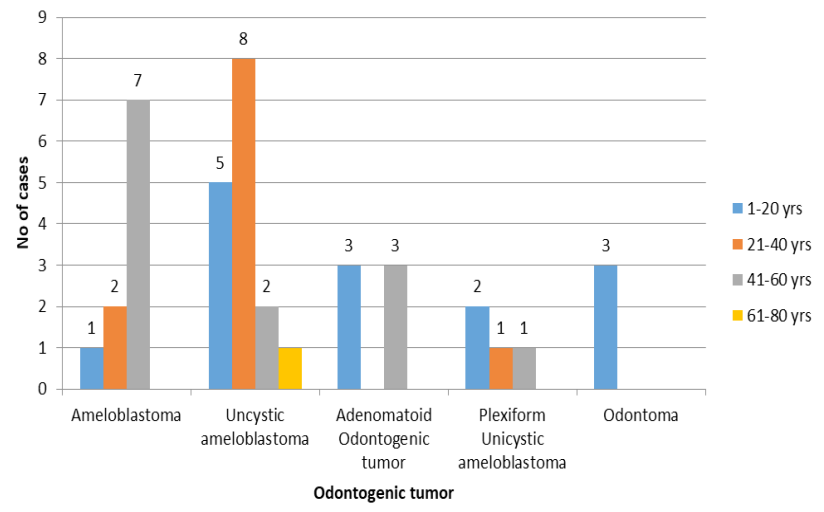

Figure 6. Distribution of odontogenic tumors among the age groups.

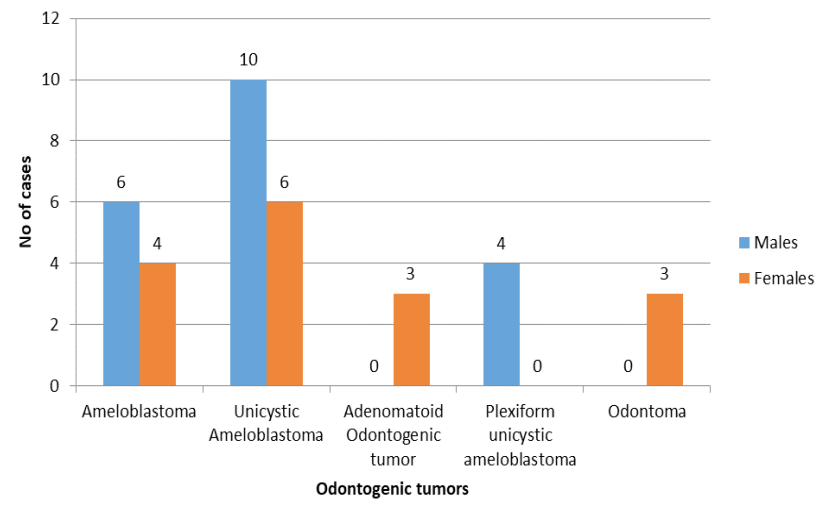

Figure 7. Frequency of odontogenic tumors based on their gender.

Among the 42 cases, $22(52.3 \%)$ cases occurred in the posterior mandible cases, $10(23.8 \%)$ cases in the anterior mandible, $3(7.1 \%)$ cases in the posterior maxilla and $1(2.3 \%)$ in the anterior maxilla (Figure 8 ).

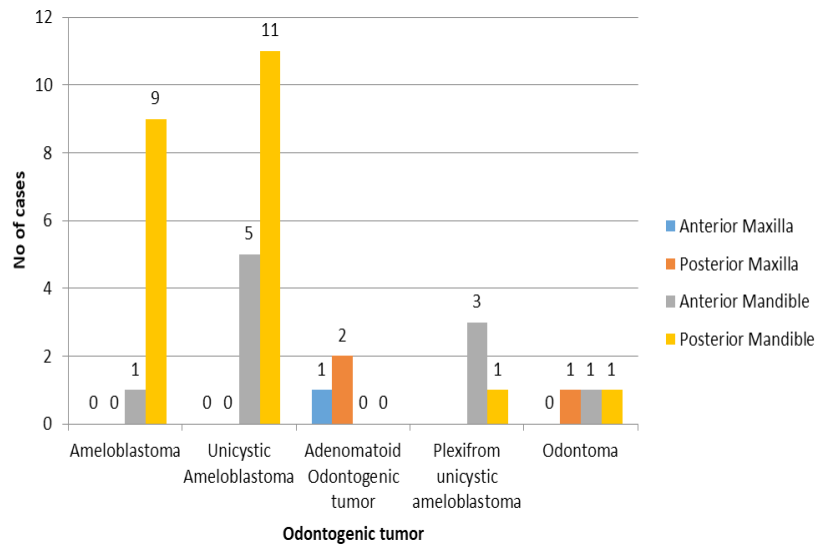

Figure 8. Distribution of odontogenic tumors based on the site of occurrence in the jawbones. 


\section{Discussion}

According to the previous studies mentioned in the literature, odontogenic cysts are diagnosed in $7 \%$ to $12 \%$ of all maxillofacial biopsies [9-11]. Radicular cyst also known as periapical cyst is the most common inflammatory cyst that results from epithelial proliferation within an inflammatory focus, due to dental caries resulting in pulpal infection leading to death and necrosis of the pulp [12]. Radicular cyst accounted for $60.8 \%$ of all cysts in our study, occurring more frequently in the anterior maxilla, which is in accordance with other studies done by Procket et al. (72.5\%) [11], Koseoglu et al. (56.9\%) [13], Jones et al. $(60.3 \%)$ [14] on UK population. In a study conducted by Al-Rawi et al. [15]. in UAE population, similar findings were obtained (69.1\%); our study is also in accordance with the study conducted by Grossmann et al. [16] in Brazilian population $(61 \%)$.

Odontogenic cysts showed male predilection (66.4\%), compared to females (32\%), which is analogous with studies conducted in other countries with frequencies ranging from 52.5 to $65.0 \%$ [9,10,14-17]. Conflicting these results, female predominance was found in the Brazilian population [18]; also, in a study conducted in Luthiana population females predominated with a ratio of 1:2.6 [10].

As per the present study the most frequently affected site is the posterior mandible ( $42.4 \%)$, followed by anterior maxilla (32\%), which is comparable with the studies done by other investigators $[10,14,15,17,18]$.

Contradictory to these results, studies conducted by Varinauskas et al. [19] maxilla was found to be the most frequently affected site with a ratio of 1.5:1, Baghaei et al. [2] and Bataineh et al. [20] reported the same pervasiveness of odontogenic cysts in both jaws. The peak incidence of odontogenic cyst in our study was found to be between 20 to 40 years, which virtually is in accordance with other studies where they found the prevalence between 30-50 years $[20,21]$.

Odontogenic tumors have variable incidence worldwide and may present regional differences. The studies done by Daley et al. [22] and Taylor et al. [23] in North America, Ochsenius et al. [24], Santos et al. [25], in South America, and Tamme et al. [26] in Europe have shown the a frequency of odontogenic tumors lower than $3 \%$. In Asia and Africa the lesions represented 8.99 and $9.6 \%$, respectively [27-29], while an Iranian series had a frequency of $1.9 \%$ and Brazil $4.8 \%$ [30].

In a survey among Brazilian population, keratocystic odontogeinc tumor was found to be more prevalent [7], which was in accordance with the studies conducted in Turkey where they found KCOT and odontomas to be prevalent [31]. Other investigations show higher prevalence of ameloblastoma, as reported by studies from Japan, Nigeria, China, Tanzania and Sri Lanka [32], which is in accordance with Chawla et al. [33] in India. In the current institutional study unicystic ameloblastoma (38\%) was found to be the most frequently occurring odontogenic tumor. It is a variant of solid multicystic ameloblastoma, less aggressive and with variable recurrence rate. It usually presents as one or more nodules of odontogenic epithelium projecting from the cyst into the cystic lumen [21].

The odontogenic tumors occurred more frequently between the age of 21-40 years, being rare after $7^{\text {th }}$ decade, with a male prevalence [33-34]; contradictory to this was the Brazilian study where they found female predominance [30]. Posterior mandible was found to be the most common site of occurrence which are comparable to other studies [28-35].

Although the lesions occurred more frequently between 21-40 years, it is remarkable that surveys carried out among population under the age of 20 years, higher prevalence of odontogenic tumors in the years has been established, which is in accordance with our study. The incidence of these tumors, in young people of Argentina, has been reported $7 \%$ and in Libya $16.4 \%$. Thus the difference in the prevalence of odontogenic tumors in different parts of the world suggests that the incidence of these lesions is probably related to the racial and environmental factors [2].

Odontogenic cyst and tumors are derived from the odontogenic tissue that constitute a diverse group of lesions, as these lesions originate through some alteration from the normal pattern of odontogenesis thus reflecting the diversity of the development of the dental structures. The diagnosis of odontogenic cyst and tumors should be based on careful examination of clinical, radiographic, and histopathological features, as many of these lesions share the same clinical and radiographical features.

\section{Conclusion}

The present study provides epidemiological information of odontogenic cysts and tumors at an institutional level. The variation in relative incidences of odontogenic cysts and tumors among different population were noted which may be attributed to the geographic variations. According to the present study we found a higher incidence of odontogenic cyst than odontogenic tumors, with a male predilection, age range of 1 to 20 years for odontogenic tumors, whereas odontogenic cysts were found more frequently between the age range of 21-40 years, posterior mandible being the most common site.

\section{References}

1. Ramachandra S, Shekar PC, Prasad S, Kumar KK, Reddy GS, Prakash KL etal. Prevalence of odontogenic cysts and tumors: A retrospective clinico-pathological study of 204 cases. SRM J of Res in Dent Sci 2014;5:170-173.

2. Baghaei F, Zargaran M, Najmi H, Moghimbeigi A. A clinicopathological study of odontogenic cysts and tumors in Hamadan, Iran. J Dent (Shiraz). 2014;15:167-172. 
3. Ravikumar H, Ravishankar MN, Shashikaran HC, Jain R. Odontogenic cysts- A clinicopathological study of 120 cases. Journal of Dental and Medical sciences. 2014; 13(5) : 77-79.

4. Nuñez-Urrutia S, Figueiredo R, Gay-Escoda C. Retrospective clinicopathological study of 418 odontogenic cysts. Med Oral Patol Oral Cir Bucal. 2010;15:e767-e773.

5. Ochsenius G, Escobar E, Godoy L, Peñafiel C. Odontogenic cysts: analysis of 2,944 cases in Chile. Med Oral Patol Oral Cir Bucal. 2007;12:E85-E91.

6. Al Sheddi MA. Odontogenic cysts. A clinicopathological study. Saudi Med J. 2012;33:304-308.

7. Ramos Gde O, Porto JC, Vieira DS, Siqueira FM, Rivero ER. Odontogenic tumors: a 14-year retrospective study in Santa Catarina, Brazil. Braz Oral Res. 2014;28:33-38.

8. Mosqueda-Taylor A. New findings and controversies in odontogenic tumors. Med Oral Patol Oral Cir Bucal. 2008;13:E555-E558.

9. Mosqueda-Taylor A, Irigoyen-Camacho ME, Diaz-Franco MA, Torres-Tejero MA. Odontogenic cysts. Analysis of 856 cases. Med Oral. 2002;7:89-96.

10. Ledesma-Montes C, Hernández-Guerrero JC, Garcés-Ortíz M. Clinico-pathologic study of odontogenic cysts in a Mexican sample population. Arch Med Res. 2000;31:373376.

11. Prockt AP, Schebela CR, Maito FD, Sant'Ana-Filho M, Rados PV. Odontogenic cysts: analysis of 680 cases in Brazil. Head Neck Pathol. 2008;2:150-156.

12. Selvamani M, Donoghue M, Basandi PS. Analysis of 153 cases of odontogenic cysts in a South Indian sample population: a retrospective study over a decade. Braz Oral Res. 2012;26:330-334.

13. Koseoglu BG, Atalay B, Erdem MA. Odontogenic cysts: a clinical study of 90 cases. J Oral Sci. 2004;46:253-257.

14. Jones AV, Craig GT, Franklin CD. Range and demographics of odontogenic cysts diagnosed in a UK population over a 30-year period. J Oral Pathol Med. 2006;35:500-507.

15. Al-Rawi NH, Awad M, Al-Zuebi IE, Hariri RA, Salah EW. Prevalence of odontogenic cysts and tumors among UAE population. J Orofac Sci. 2013;5:95-100.

16. Grossmann SM, Machado VC, Xavier GM, Moura MD, Gomez RS, Aguiar MC, et al. Demographic profile of odontogenic and selected nonodontogenic cysts in a Brazilian population. Oral Surg Oral Med Oral Pathol Oral Radiol Endod. 2007;104:e35-e41.

17. Tortorici S, Amodio E, Massenti MF, Buzzanca ML, Burruano F, Vitale F. Prevalence and distribution of odontogenic cyst in Sicily: 1986-2005. J Oral Sci. 2008;50:15-18.

18. de Souza LB, Gordón-Núñez MA, Nonaka CF, de Medeiros MC, Torres TF, Emiliano GB. Odontogenic cysts: demographic profile in a Brazilian population over a 38-year period. Med Oral Patol Oral Cir Bucal. 2010;15:e583-e590.

19. Varinauskas V, Gervickas A, Kavoliūniene O. Analysis of odontogenic cysts of the jaws. Medicina (Kaunas). 2006;42:201-207.

20. Bataineh AB, Rawashdeh MA, Al Qudah MA. The prevalence of inflammatory and developmental odontogenic cysts in a Jordanian population: a clinicopathologic study. Quintessence Int. 2004;35:815-819.

21. Ricci M, Mangano F, Tonelli P, Barone A, Galletti C, Covani U. An unusual case of unicystic intramural ameloblastoma and review of the literature. Contemp Clin Dent. 2012;3(Suppl 2):S233-S239.

22. Daley TD, Wysocki GP, Pringle GA. Relative incidence of odontogenic tumors and oral and jaw cysts in a Canadian population. Oral Surg Oral Med Oral Pathol. 1994;77:276280.

23. Mosqueda-Taylor A, Ledesma-Montes C, CaballeroSandoval S, Portilla-Robertson J, Ruíz-Godoy Rivera LM, Meneses-García A. Odontogenic tumors in Mexico: a collaborative retrospective study of 349 cases. Oral Surg Oral Med Oral Pathol Oral Radiol Endod. 1997;84:672-675.

24. Ochsenius G, Ortega A, Godoy L, Peñafiel C, Escobar E. Odontogenic tumors in Chile: a study of 362 cases. J Oral Pathol Med. 2002;31:415-420.

25. Santos JN, Pinto LP, de Figueredo CR, de Souza LB. Odontogenic tumors: analysis of 127 cases. Pesqui Odontol Bras. 2001;15:308-313.

26. Tamme T, Soots R, Kulla A, Karu K, Hanstein SM, Sokk A, et al. Odontogenic tumors, a collaborative retrospective study of 75 cases covering more than 25 years from Estonia. J Craniomaxillofac Surg. 2004;32:161-165.

27. Ladeinde AL, Ajayi OF, Ogunlewe MO, Adeyemo WL, Arotiba GT, Bamgbose BO, et al. Odontogenic tumors: a review of 319 cases in a Nigerian teaching hospital. Oral Surg Oral Med Oral Pathol Oral Radiol Endod. 2005;99:191-195.

28. Luo HY, Li TJ. Odontogenic tumors: a study of 1309 cases in a Chinese population. Oral Oncol. 2009;45:706-711.

29. Saghravanian N, Jafarzadeh H, Bashardoost N, Pahlavan N, Shirinbak I. Odontogenic tumors in an Iranian population: a 30-year evaluation. J Oral Sci. 2010;52:391-396.

30. da Silva LP, Serpa MS, Tenório JR, do Nascimento GJ, de Souza-Andrade ES, Veras-Sobral AP. Retrospective study of 289 odontogenic tumors in a Brazilian population. Med Oral Patol Oral Cir Bucal. 2016;21:e271-e275.

31. Şenel FC, Dayisoylu EH, Ersöz S, Altintaş NY, Tosun E, Ungör C, Taşkesen F. The relative frequency of odontogenic tumors in the Black Sea region of Turkey: an analysis of 86 cases.

32. Taghavi N, Rajabi M, Mehrdad L, Sajjadi S. A 10-year retrospective study on odontogenic tumors in Iran. Indian J Dent Res. 2013;24:220-224.

33. Chawla R, Ramalingam K, Sarkar A, Muddiah S. Ninetyone cases of ameloblastoma in an Indian population: A comprehensive review. J Nat Sci Biol Med. 2013;4:310-315.

34. Lawal AO, Adisa AO, Olusanya AA. Odontogenic tumors: A review of 266 cases. J Clin Exp Dent. 2013;5:e13-e17.

35. Johnson NR, Savage NW, Kazoullis S, Batstone MD. A prospective epidemiological study for odontogenic and non-odontogenic lesions of the maxilla and mandible in Queensland. Oral Surg Oral Med Oral Pathol Oral Radiol. 2013;115:515-522. 